Research Paper

\title{
Enhanced alkaline cellulases production by the thermohalophilic Aspergillus terreus AUMC 10138 mutated by physical and chemical mutagens using corn stover as substrate
}

\author{
George Saad Isaac, Medhat Ahmed Abu-Tahon \\ Biological and Geological Sciences Department, Faculty of Education, Ain Shams University, \\ Cairo, Egypt.
}

Submitted: November 19, 2014; Approved: May 6, 2015.

\begin{abstract}
A thermohalophilic fungus, Aspergillus terreus AUMC 10138, isolated from the Wadi El-Natrun soda lakes in northern Egypt was exposed successively to gamma and UV-radiation (physical mutagens) and ethyl methan-sulfonate (EMS; chemical mutagen) to enhance alkaline cellulase production under solid state fermentation (SSF) conditions. The effects of different carbon sources, initial moisture, incubation temperature, initial $\mathrm{pH}$, incubation period, inoculum levels and different concentrations of $\mathrm{NaCl}$ on production of alkaline filter paper activity (FPase), carboxymethyl cellulase (CMCase) and $\beta$-glucosidase by the wild-type and mutant strains of $A$. terreus were evaluated under SSF. The optimum conditions for maximum production of FPase, CMCase and $\beta$-glucosidase were found to be the corn stover: moisture ratio of $1: 3(\mathrm{w} / \mathrm{v})$, temperature $45^{\circ} \mathrm{C}, \mathrm{pH}$ range, $9.0-11.0$, and fermentation for 4,4 and 7 day, respectively. Inoculum levels of $30 \%$ for $\beta$-glucosidase and $40 \%$ for FPase, CMCase gave the higher cellulase production by the wild-type and mutant strains, respectively. Higher production of all three enzymes was obtained at a $5 \% \mathrm{NaCl}$. Under the optimized conditions, the mutant strain $A$. terreus $\mathrm{M}-17$ produced FPase $(729 \mathrm{U} / \mathrm{g})$, CMCase $(1,783 \mathrm{U} / \mathrm{g})$, and $\beta$-glucosidase ( $342 \mathrm{U} / \mathrm{g}$ ), which is, 1.85, 1.97 and 2.31-fold higher than the wild-type strain. Our results confirmed that mutant strain M-17 could be a promising alkaline cellulase enzyme producer employing lignocellulosics especially corn stover.
\end{abstract}

Key words: thermohalophilic fungus, Aspergillus terreus, alkaline cellulase, solid state fermentation, corn stover.

\section{Introduction}

Soda lakes are widely distributed all over the world and represent the major type of naturally occurring highly alkaline environments in which the indigenous microflora is subjected to a number of extreme ecological pressures. The lakes represent the most stable high-pH environments on Earth, where large amounts of carbonate minerals can generate $\mathrm{pH}$ values higher than 11.5 (Grant and Jones, 2000). These environments exhibit extreme temperature, $\mathrm{pH}$ and salt content, and enzymes produced by microorganisms have evolved to function optimally under harsh conditions (Zhang et al., 2006). One of such environmental niches which has not been studied in detail is represented by the Wadi El-Natrun soda lakes in northern Egypt. The ecosystem of Wadi El-Natrun area is considered a rich source for isolation of various extremophiles, including alkalophilic microorganisms.

Cellulase enzymes, which can hydrolyze cellulose forming glucose and other commodity chemicals, can be divided into three types: endoglucanase (endo-1,4- $\beta$-Dglucanase, EG, EC 3.2.1.4); cellobiohydrolase (exo-1,4- $\beta$ D-glucanase,CBH, EC 3.2.1.91) and $\beta$-glucosidase $(1,4-$ $\beta$-D-glucosidase, BG, EC 3.2.1.21) (Hong et al., 2001; Li et al., 2006). Lignocellulosic biomass, especially agricultural 
wastes, is known to be an excellent carbon source for microbial enzyme production; and lignocellulosic biomass, such as corn cob, corn stover and wheat bran, are very abundant, cheap and easily available. Various agricultural substrates-byproducts and microbial cultures have been successfully used in the solid state fermentation (SSF) for cellulase production (Yang et al., 2006).

Cellulase production has been described for many Aspergillus species (Ong et al., 2004; Wang et al., 2006; Gao et al., 2008). A. terreus has been shown to be the best producer of cellulase as compared to other microorganisms (Mizaakhmedov et al., 2007), although only few reports available on production of cellulase from A. terreus, especially under SSF conditions (Emtiazi et al., 2001). Also, cellulase research has focused on halophilic enzymes only to a very limited extent (Wang et al., 2006).

Strain improvement is usually achieved by mutating the microorganism that produces the enzyme by classical mutagenesis, generally involves exposing the microbe to physical mutagens (e.g., X-rays, $\gamma$-rays, UV-rays, etc.), and/or chemical mutagens (e.g., nitroglycerin, ethyl methanesulfonate (EMS), etc.; Parekh et al., 2004; Adsul et al., 2007; Raghuwanshi et al., 2014). Hydrolysis of cellulose to soluble sugars makes it available as a feedstock for alcoholic fermentation, single cell protein production, and other industrial processes (Louime and Uckelmann, 2008). The utilization of cellulosic biomass for ethanol production continues to be a subject of worldwide interest in view of fast depletion of oil reserves and food shortages (Singh et al., 2009). In the present study, we evaluated the potential of A. terreus AUMC 10138, an alkalophilic and salttolerant fungus, isolated from the Wadi El-Natrun soda lakes in northern Egypt, for cellulase production and attempted to improve the enzyme yield by physical ( $\gamma$-rays and UV-rays) and chemical (EMS) mutagenesis of the microorganism. We also optimized culture conditions for the mutant and wild-type strains using corn stover as a substrate under solid state fermentation.

\section{Materials and Methods}

\section{Strain isolation and identification}

Soil samples were collected from different regions of the Wadi El-Natrun soda lakes in northern Egypt. Isolation of alkalophilic fungi was carried out using carboxymethyl cellulose $(\mathrm{CMC})$ medium containing $(\mathrm{g} / \mathrm{L})$; yeast extract, $2.5 \mathrm{~g}$; tryptone, $2.5 \mathrm{~g}$; $\left(\mathrm{NH}_{4}\right)_{2} \mathrm{SO}_{4}, 1.0 \mathrm{~g} ; \mathrm{KH}_{2} \mathrm{PO}_{4}, 0.5 \mathrm{~g}$; $\mathrm{K}_{2} \mathrm{HPO}_{4}, 0.5 \mathrm{~g}, \mathrm{MgSO}_{4}, 0.2 \mathrm{~g}$; CMC (Sigma, USA), $5 \mathrm{~g}$, and supplemented with $5 \% \mathrm{NaCl}$ and $1.5 \%$ agar (w/v). $\mathrm{pH}$ was adjusted to 9.0 using $1 \mathrm{M} \mathrm{KOH}$. Briefly, $10 \mathrm{~g}$ of a soil sample was added to $90 \mathrm{~mL}$ of sterile water, agitated for $1 \mathrm{~h}$ at $250 \mathrm{rpm}$, and then $1.0 \mathrm{~mL}$ of the suspension was spread on a $\mathrm{CMC}$ agar plate. All plates were incubated at $45^{\circ} \mathrm{C}$ un- til colonies with a distinct clearing zone was visible. A colony of A. terreus (designated as AUMC10138) with the largest halo zone was picked and purified for further study (data not shown). The ability of the isolate to secrete cellulase was evaluated on a Congo red plate according to Kasana et al. (2008). The purified isolates were maintained on potato dextrose agar (PDA) at $4{ }^{\circ} \mathrm{C}$ and were subcultured at monthly intervals. The identification was carried out by the Assiut University Mycological Centre (AUMC), Egypt.

\section{Fungal strain and media}

A. terreus AUMC 10138 was maintained on PDA medium at $45^{\circ} \mathrm{C}$ for 7 days for spore production. Conidial suspensions were prepared by washing slant cultures with $10 \mathrm{~mL}$ of a sterilized $0.9 \% \mathrm{NaCl}(\mathrm{w} / \mathrm{v})$ solution. A spore suspension was counted at $10^{5}-10^{6}$ spores $/ \mathrm{mL}$ by a haemocytometer.

\section{Fungal strain improvement by mutagenesis}

Spores of $A$. terreus $\left(10^{5}-10^{6}\right.$ spores $\left./ \mathrm{mL}\right)$ were harvested from a 7 day-old spores grown on PDA medium following exposure to different doses $(0.25 \sim 2.5 \mathrm{kGy})$ of $\mathrm{Co}^{60}$ $\gamma$-rays emitted by an Indian gamma cell located at the National Center for Radiation Research and Technology (NCRRT), Nasr City, Cairo, Egypt. Survivors were grown by spreading $1.0 \mathrm{~mL}$ of the treated spores on $\mathrm{CMC}$ medium and incubating at $45^{\circ} \mathrm{C}$ for 7 days. Mutants with the largest clear zones around the colonies and cellulase production were selected and re-irradiated with $\mathrm{Co}^{60} \gamma$-rays. The best surviving mutant was then exposed to UV-radiation (power: $30 \mathrm{~W}$, wavelength: $260 \mathrm{~nm}$ at a distance of $20 \mathrm{~cm}$ for 2 30 min). Selected UV mutants were treated with EMS (20 $\mathrm{mg}$ were added to $10 \mathrm{~mL}$ of suspension containing $10^{5}-10^{6}$ spores $/ \mathrm{mL}$ ). The mutant spores were washed four times with a saline solution and spread on $\mathrm{CMC}$ medium as described above. A mutant displaying high cellulase activity after the mutagenic treatments was selected, and stability of the enzyme production was studied for nine generations by successive inoculations of the strain on cellulase production medium.

\section{Substrates}

The lignocellulosic substrates, namely, corn cob, corn stover, saw dust, sugar cane bagasse and wheat straw, were all obtained locally. They were dried and chopped into small pieces, then ground into smaller particles in a hammer mill, and finally separated using a $0.45 \mathrm{~mm}$ ( $40 \mathrm{mesh}$ ) sieve. The fraction that passed through the sieve was used for SSF medium preparation.

\section{Medium and cultivation conditions}

A dry carbon source $(5 \mathrm{~g})$ was amended with $10 \mathrm{~mL}$ of a mineral salt solution containing $(\mathrm{g} / \mathrm{L}) ;\left(\mathrm{NH}_{4}\right)_{2} \mathrm{SO}_{4}$, $3.5 \mathrm{~g} ; \mathrm{KH}_{2} \mathrm{PO}_{4}, 3 \mathrm{~g} ; \mathrm{MgSO}_{4} .7 \mathrm{H}_{2} \mathrm{O}, 0.5 \mathrm{~g}, \mathrm{CaCl}_{2}, 0.5 \mathrm{~g}$ and 
supplemented with $5 \% \mathrm{NaCl}$, (pH 9.0). The mixture was placed in $250 \mathrm{~mL}$ Erlenmeyer flask, mixed homogenously and sterilized at $121{ }^{\circ} \mathrm{C}$ for $15 \mathrm{~min}$ (Juhasz et al., 2005). One milliliter of prepared spores from wild and selected mutant strain M17 was inoculated and incubated at $45{ }^{\circ} \mathrm{C}$ under static conditions. The best solid substrate was selected and used in subsequent experiments.

\section{Optimization of SSF}

SSF was carried out to study the effects of various physico-chemical parameters required for the maximal cellulase production by $A$. terreus AUMC10138 and its most potent mutant strain M-17. The parameters that were optimized were the substrate (corn cob, corn stover, saw dust, sugar cane bagasse, wheat straw), initial moisture $(1: 1,1: 2,1: 3,1: 4$ and $1: 5 \mathrm{w} / \mathrm{v}$, where $\mathrm{v}$ and $\mathrm{w}$ represent water and water + dried corn stover, respectively), incubation temperature $\left(25 \sim 55^{\circ} \mathrm{C}\right)$, initial $\mathrm{pH}(7 \sim 12)$, incubation period ( $2 \sim 9$ days), inoculum level $(10 \sim 50 \%, \mathrm{v} / \mathrm{w})$ and concentrations of $\mathrm{NaCl}(0 \sim 15.0 \%)$. Each experiment was performed in triplicate.

\section{Enzyme extract}

The solid substrate culture broth was prepared by adding 10 -fold $(\mathrm{v} / \mathrm{w})$ of distilled water and shaking the mixture $(200 \mathrm{rpm})$ at $30^{\circ} \mathrm{C}$ for $60 \mathrm{~min}$. Then, the solid materials and fungal biomass were separated by centrifugation $(10,000 \times \mathrm{g}, 15 \mathrm{~min})$, and the clarified supernatant was used for enzyme assays.

\section{Enzyme assay}

The activities of total cellulase (filter paper activity, endoglucanase and $\beta$-glucosidase were determined as reported earlier (Grajek, 1987). FPase activity was assayed by incubating $1 \mathrm{~mL}$ of a suitably diluted enzyme solution with Tris- $\mathrm{HCl}$ buffer $(20 \mathrm{mM}, \mathrm{pH}$ 9.0) containing Whatman No. 1 filter paper $(50 \mathrm{mg}, 1 \times 6 \mathrm{~cm})$. The reaction mixture was incubated at $60^{\circ} \mathrm{C}$ for $30 \mathrm{~min}$. Endoglucanase (CMCase, endo-1,4- $\beta$-D-glucanase; EC 3.2.1.4) activity was measured in a total reaction volume of $1 \mathrm{~mL}$ containing $0.5 \mathrm{~mL}$ of suitably diluted enzyme and $0.5 \mathrm{~mL}$ of $1 \%(\mathrm{w} / \mathrm{v})$ carboxymethyl cellulose $(\mathrm{CMC})$ solution in Tris- $\mathrm{HCl}$ buffer $(20 \mathrm{mM}, \mathrm{pH} 9.0)$. The mixture was incubated at $60{ }^{\circ} \mathrm{C}$ for $30 \mathrm{~min}$. The release of reducing sugars was determined by the 3,5-dinitrosalicylic acid (DNS) method (Miller, 1959). $\beta$-Glucosidase ( $\beta$-D-glucoside, glucohydrolase; EC3.2.1.21) activity was estimated using $p$-nitrophenyl$\beta$-Dglucopyranoside (pNPG) a substrate. An assay mixture $(1 \mathrm{~mL})$ consisting of $0.9 \mathrm{~mL}$ of $p$ NPG $(1 \mathrm{mM})$ and $0.1 \mathrm{~mL}$ of suitably diluted enzyme was incubated at $60{ }^{\circ} \mathrm{C}$ for $30 \mathrm{~min}$. The $p$-nitrophenol liberated was measured at $420 \mathrm{~nm}$ after developing the color in the presence of $2 \mathrm{~mL}$ of sodium carbonate $(2 \mathrm{M})$. One unit $(\mathrm{U})$ of enzyme activity was defined as the amount of enzyme required to liberate $1 \mu \mathrm{mol}$ of glucose or $p$-nitrophenol from the appropriate substrates per minute under the assay conditions.

\section{Statistical analysis}

The data obtained were statistically analyzed with SPSS (Scientific Package for Scientific Social Studies, version 20), in which the equations of the hypothesis tests, including the mean, standard deviation, T-statistics value and probabilities (p) were used.

\section{Results and Discussion}

\section{Screening of mutants for cellulase}

The use of mutagenesis and selection has been found effective in increasing cellulase production by microorganisms (Vu et al., 2011; Raghuwanshi et al., 2014). In the present study, wild-type strain A. terreus AUMC10138 was subjected to mutagenesis by using $\mathrm{Co}^{60} \gamma$-rays, UV-irradiation and EMS (data not shown). Six mutants were selected (M-14, M-15, M-16, M-17, M-18 and M-19) which showed increased production of FPase, CMCase and $\beta$-glucosidase. Mutant M-17 was selected on the basis of improved enzyme production and the largest clear zone. $A$. terreus M-17 showed a 1.98, 2.43 and 2.35-fold increase in

Table 1 - Alkaline cellulase production under liquid state cultivation by A. terreus AUMC 10138 and its most potent mutants.

\begin{tabular}{lcccccc}
\hline Strain & & Zone of clearance $(\mathrm{mm})$ & \multicolumn{3}{c}{ Enzyme activity $(\mathrm{U} / \mathrm{mL})$} \\
\cline { 1 - 1 } Wild & Mutant & & CMCase & & FPase & $\beta$-Glucosidase \\
\hline AUMC 10150 & - & 18 & $1.11 \pm 0.12$ & $0.46 \pm 0.17$ & $0.23 \pm 0.10$ \\
& M14 & 23 & $1.53 \pm 0.15$ & $0.66 \pm 0.11$ & $0.33 \pm 0.09$ \\
& M15 & 21 & $1.67 \pm 0.11$ & $0.72 \pm 0.13$ & $0.37 \pm 0.15$ \\
& M16 & 21 & $1.85 \pm 0.17$ & $0.84 \pm 0.15$ & $0.42 \pm 0.18$ \\
M17 & 21 & $2.20 \pm 0.24$ & $1.12 \pm 0.13$ & $0.54 \pm 0.10$ \\
& M18 & 20 & $1.93 \pm 0.10$ & $0.97 \pm 0.12$ & $0.39 \pm 0.14$ \\
M19 & & $1.70 \pm 0.18$ & $0.68 \pm 0.27$ & $0.26 \pm 0.15$ \\
\hline
\end{tabular}


FPase, CMCase and $\beta$-glucosidase activities, respectively, compared to the wild-type strain (Table 1).

\section{Genetic stability of the selected mutant strain}

The stability of cellulase production by selected mutant M-17 was studied by successive subculturing of the strain for nine generations. After each subculture, the mutant was tested for its stability to produce cellulase. The mutant maintained the same production yields after being subcultured nine times; indicating hereditary stability of the mutation has (Table 2).

\section{Effect of carbon source}

Cellulase production was found to be dependent on the nature of the carbon source used in the culture medium (Gao et al., 2008). The influence of various carbon sources on the cellulase production by both wild-type and mutant strains of $A$. terreus is shown in Table 3. Corn stover was the best carbon source for FPase, CMCase and $\beta$-glucosidase production among the tested lignocellulosic materials. This might be attributed to its hemicellulose nature, favorable degradability, and the presence of certain nutrients in corn stover (Senthilkumar et al., 2005). Corn stover is composed of approximately $39.54 \%$ of cellulose, $25.76 \%$ of hemicellulose, $17.49 \%$ of lignin, and $5.04 \%$ of ash (Yang, 2001). Besides, the efficiency of enzyme production also depends on the chemical composition of a raw ma- terial, accessibility of various components and their chemical or physical associations, corn stover has been known as an ideally suitable substrate for cellulase production (Gao et al., 2008; Liu et al., 2011). In this study corn stover induced maximum FPase (140 U/g), CMCase (330 U/g) and $\beta$-glucosidase $(66 \mathrm{U} / \mathrm{g})$ production by the wild-type strain of $A$. terreus. In the case of mutant strain M-17, the maximum FPase (267 U/g), CMCase (561 U/g) and $\beta$-glucosidase $(132 \mathrm{U} / \mathrm{g})$ production was also obtained on corn stover as a carbon source.

\section{Effect of initial moisture content}

The initial moisture content plays an important role in biosynthesis and secretion of many kinds of enzymes, especially cellulases (Vu et al., 2011). Therefore, the effect of moisture content on the cellulase production by $A$. terreus AUMC10138 and mutant M-17 was analyzed. The results showed that an increase in the initial moisture ratio from $1: 1$ to $1: 3(\mathrm{w} / \mathrm{v})$ greatly enhanced the production of all three cellulases. The substrate to moisture ratio of $1: 3$ resulted in the maximum production of FPase $(163 \mathrm{U} / \mathrm{g})$, CMCase (390 U/g) and $\beta$-glucosidase $(78 \mathrm{U} / \mathrm{g}$ ) by the wild-type strain. Similarly, mutant strain M-17 also produced FPase (293 U/g), CMCase (702 U/g) and $\beta$-glucosidase (178 U/g) maximally at a substrate to moisture ratio of $1: 3(\mathrm{w} / \mathrm{v})$. Any further increase in the moisture level in SSF led to decreased enzyme production (Table 4). This might be due to

Table 2 - Alkaline cellulase activities of most potent mutant $A$. terreus $\mathrm{M}-17$ for nine generations.

\begin{tabular}{|c|c|c|c|c|c|c|c|c|c|}
\hline \multirow[t]{2}{*}{ Cellulolytic enzymes } & \multicolumn{9}{|c|}{ Enzyme activity $(\mathrm{U} / \mathrm{mL})$ in nine generations } \\
\hline & $1 \mathrm{st}$ & 2 nd & $3 \mathrm{rd}$ & 4 th & 5 th & 6th & 7th & 8th & 9th \\
\hline \multirow[t]{2}{*}{ CMCase } & 2.20 & 2.13 & 2.10 & 2.12 & 2.15 & 2.18 & 2.22 & 2.22 & 2.24 \\
\hline & \pm 0.20 & \pm 0.02 & \pm 0.10 & \pm 0.12 & \pm 0.05 & \pm 0.30 & \pm 0.26 & \pm 0.34 & \pm 0.31 \\
\hline \multirow[t]{2}{*}{ FPase } & 1.10 & 1.12 & 1.11 & 1.12 & 1.13 & 1.10 & 1.12 & 1.11 & 1.13 \\
\hline & \pm 0.30 & \pm 0.13 & \pm 0.02 & \pm 0.05 & \pm 0.06 & \pm 0.31 & \pm 0.13 & \pm 0.09 & \pm 0.08 \\
\hline \multirow[t]{2}{*}{$\beta$-glucosidase } & 0.54 & 0.54 & 0.53 & 0.53 & 0.55 & 0.56 & 0.54 & 0.55 & 0.55 \\
\hline & \pm 0.10 & \pm 0.09 & \pm 0.18 & \pm 0.14 & \pm 0.11 & \pm 0.16 & \pm 0.09 & \pm 0.12 & \pm 0.22 \\
\hline
\end{tabular}

Table 3 - Effect of different carbon sources on alkaline cellulase production by wild-type A. terreus AUMC 10138 and its mutant strain M-17 under solid state fermentation.

\begin{tabular}{|c|c|c|c|c|c|c|}
\hline \multirow[t]{3}{*}{ Carbon source $(\mathrm{g})$} & \multicolumn{6}{|c|}{ Enzyme yield (U/g dry carbon source) } \\
\hline & \multicolumn{2}{|c|}{ CMCase } & \multicolumn{2}{|c|}{ FPase } & \multicolumn{2}{|c|}{$\beta$-Glucosidase } \\
\hline & Wild & Mutant & Wild & Mutant & Wild & Mutant \\
\hline Corn cob & $282 \pm 3$ & $479 \pm 9$ & $97 \pm 5$ & $191 \pm 4$ & $30 \pm 6$ & $69 \pm 2$ \\
\hline Corn stover & $330 \pm 5$ & $561 \pm 11$ & $140 \pm 4$ & $267 \pm 3$ & $66 \pm 7$ & $132 \pm 5$ \\
\hline Saw dust & $266 \pm 4$ & $500 \pm 9$ & $76 \pm 9$ & $134 \pm 2$ & $34 \pm 3$ & $78 \pm 4$ \\
\hline Sugarcane bagasse & $163 \pm 10$ & $326 \pm 8$ & $48 \pm 7$ & $86 \pm 3$ & $19 \pm 6$ & $45 \pm 2$ \\
\hline Wheat straw & $215 \pm 5$ & $451 \pm 8$ & $63 \pm 2$ & $153 \pm 9$ & $27 \pm 8$ & $71 \pm 8$ \\
\hline
\end{tabular}


Table 4 - Effect of initial moisture content on alkaline cellulase production by wild-type A. terreus AUMC 10138 and its mutant strain M-17 under SSF.

\begin{tabular}{|c|c|c|c|c|c|c|}
\hline \multirow[t]{3}{*}{ Substrate: moisture ratio } & \multicolumn{6}{|c|}{ Enzyme yield (U/g dry carbon source) } \\
\hline & \multicolumn{2}{|c|}{ CMCase } & \multicolumn{2}{|c|}{ FPase } & \multicolumn{2}{|c|}{$\beta$-Glucosidase } \\
\hline & Wild & Mutant & Wild & Mutant & Wild & Mutant \\
\hline $1: 1$ & $301 \pm 9$ & $511 \pm 3$ & $120 \pm 5$ & $210 \pm 6$ & $48 \pm 4$ & $86 \pm 8$ \\
\hline $1: 20$ & $330 \pm 5$ & $561 \pm 7$ & $140 \pm 4$ & $267 \pm 3$ & $66 \pm 7$ & $132 \pm 5$ \\
\hline $1: 3$ & $390 \pm 7$ & $702 \pm 9$ & $163 \pm 6$ & $293 \pm 8$ & $78 \pm 2$ & $178 \pm 6$ \\
\hline $1: 4$ & $308 \pm 8$ & $616 \pm 6$ & $126 \pm 3$ & $230 \pm 4$ & $58 \pm 6$ & $125 \pm 8$ \\
\hline $1: 5$ & $250 \pm 4$ & $475 \pm 8$ & $100 \pm 3$ & $201 \pm 2$ & $41 \pm 7$ & $93 \pm 3$ \\
\hline
\end{tabular}

steric hindrance of the cell growth, which results in reduction in the solid matrix porosity which interferes with oxygen transfer that in turn influences cell growth and metabolism, thus inhibiting the enzyme production (Xin and Geng, 2010). Similar results were obtained by Raghuwanshi et al. (2014) who reported that the maximum FPase, CMCase and $\beta$-glucosidase production by Trichoderma asperellum RCK2011and mutant SR1-7 was observed under SSF at a substrate to moisture ratio of $1: 2.5$.

\section{Effect of incubation temperature}

Temperature was the most important physical variable in the SSF. The wild-type strain showed the maximum production of FPase (163 U/g), CMCase (390 U/g) and $\beta$-glucosidase $(78 \mathrm{U} / \mathrm{g})$ at $45^{\circ} \mathrm{C}$. Likewise, mutant strain M-17 produced the maximum levels of FPase $(293 \mathrm{U} / \mathrm{g})$, CMCase $(702 \mathrm{U} / \mathrm{g})$ and $\beta$-glucosidase $(160 \mathrm{U} / \mathrm{g})$ at $45^{\circ} \mathrm{C}$. As soon as the temperature was above $45^{\circ} \mathrm{C}$, cellulase production markedly declined in both wild-type and mutant strains (Figure 1). The maximal cellulase production occurred at $45^{\circ} \mathrm{C}$ which was in the range of the temperature of thermophilic fungi (Maheshwari et al., 2000). Our results are also in agreement with those by Gao et al. (2008) who reported that the optimum temperature range for cellulase production by $A$. terreus under SSF to be $35-45^{\circ} \mathrm{C}$.

\section{Effect of initial $\mathrm{pH}$}

The $\mathrm{pH}$ of the medium is one of the most critical factors affecting fungal growth, enzyme production and transport of various components across the cell membrane (Juhasz et al., 2004). The wild-type strain showed the maximum production of FPase $(163 \mathrm{U} / \mathrm{g})$ at $\mathrm{pH} 9.0$, and the maximum production of CMCase $(470 \mathrm{U} / \mathrm{g})$ and $\beta$-glucosidase (92 U/g) at pH 10.0. However, mutant strain M-17 exhibited the maximum FPase $(378 \mathrm{U} / \mathrm{g})$ and CMCase $(893 \mathrm{U} / \mathrm{g})$ production at $\mathrm{pH} 10.0$, whereas the maximum $\beta$-glucosidase production $(195 \mathrm{U} / \mathrm{g}$ ) was observed at the initial $\mathrm{pH}$ 11.0 (Figure 2). These results clearly confirmed the alkalophilic nature of the cellulases produced by $A$. terreus and its mutant strain M-17.

\section{Effect of incubation period}

The effect of incubation period on cellulase production under SSF was evaluated. The incubation periods of
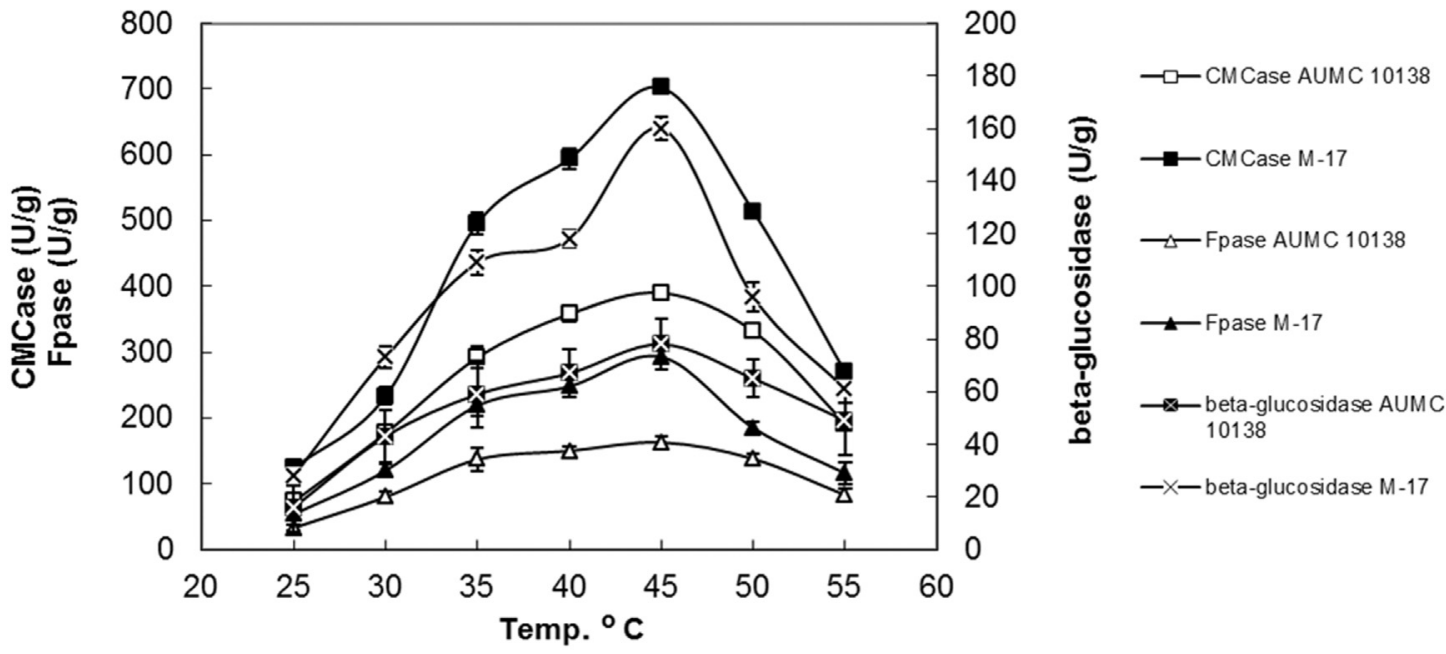

Figure 1 - Effect of the incubation temperature on alkaline cellulase production by wild-type A. terreus AUMC 10138 and its mutant strain M-17. 


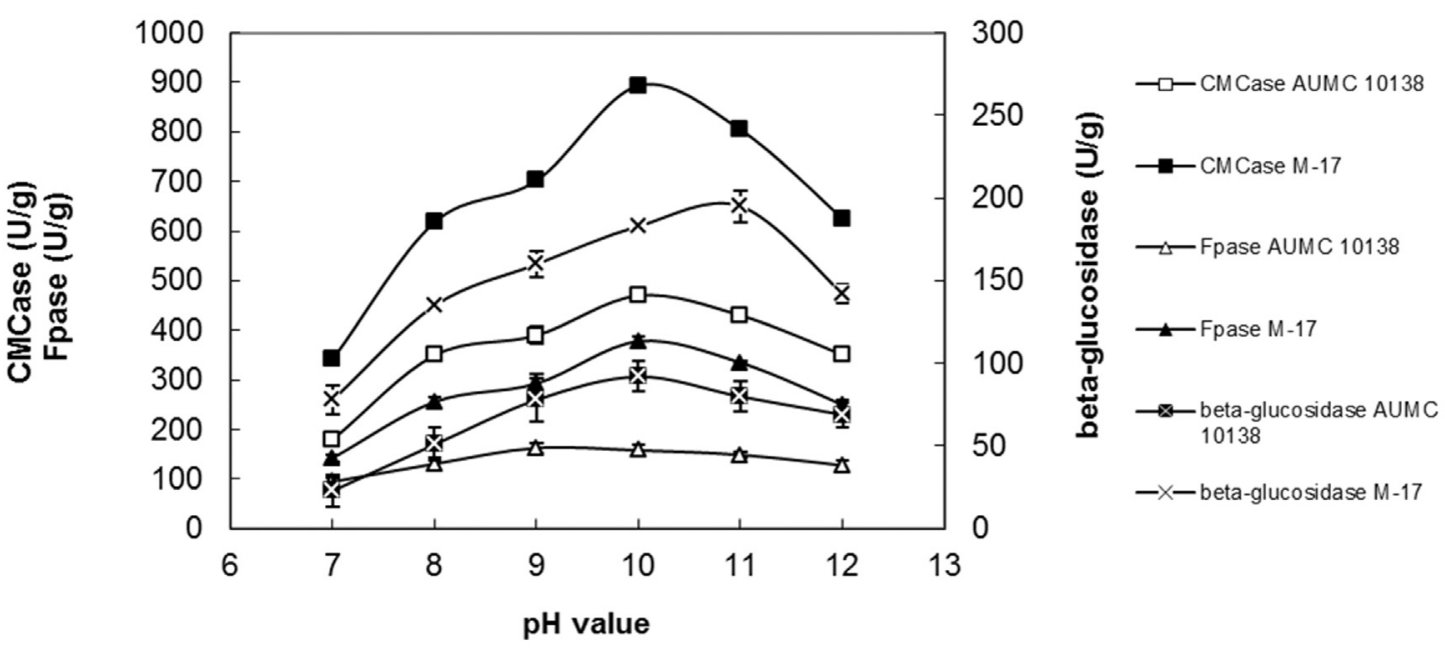

Figure 2 - Effect of the initial pH value on alkaline cellulase production by wild-type A. terreus AUMC 10138 and its mutant strain M-17.

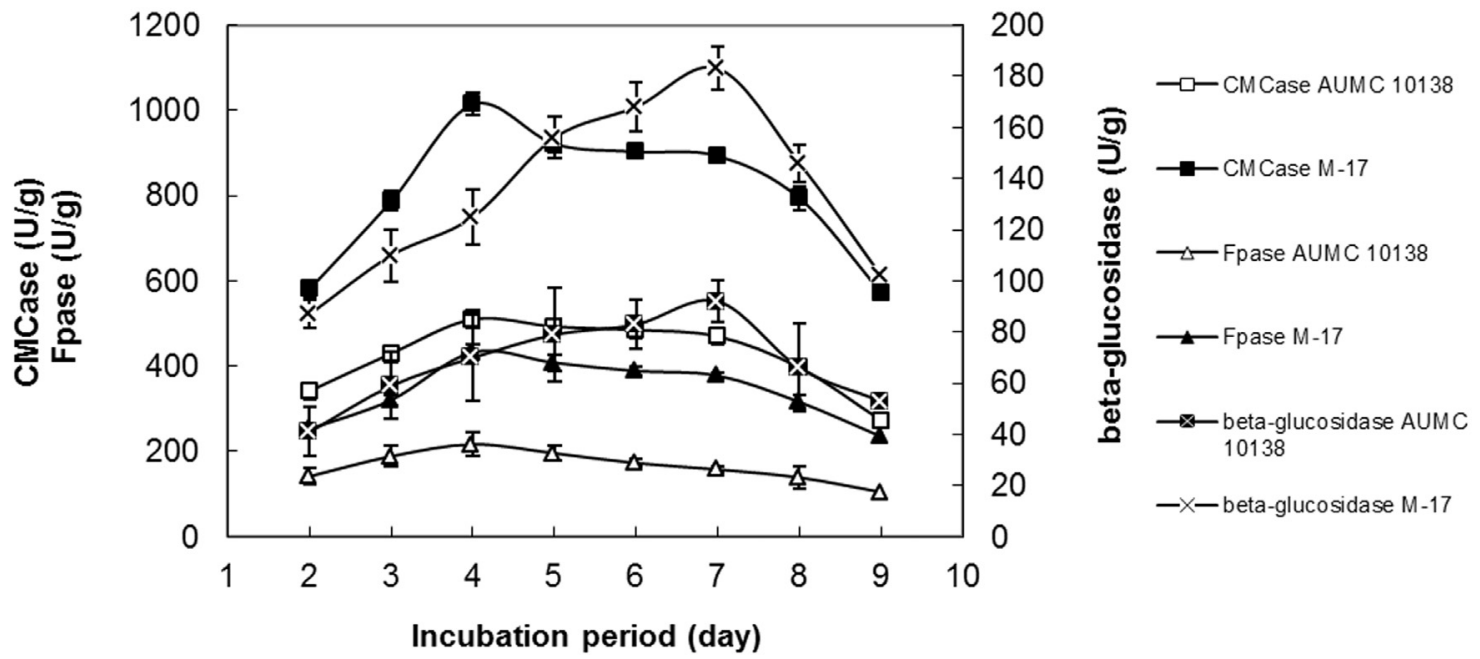

Figure 3 - Effect of the incubation periods on alkaline cellulase production by wild-type A. terreus AUMC 10138 and its mutant strain M-17.

FPase, CMCase and $\beta$-glucosidase production were shown in Figure 3. The wild-type strain exhibited the maximum FPase $(217 \mathrm{U} / \mathrm{g})$ and CMCase $(510 \mathrm{U} / \mathrm{g})$ on 4 th day of incubation, while $\beta$-glucosidase production reached maximum (92 U/g) on 7th day. Mutant M-17 behaved similarly to the wild-type and reached the peak enzyme production on 4th day with FPase $(433 \mathrm{U} / \mathrm{g})$ and CMCase $(1,014 \mathrm{U} / \mathrm{g})$, while $\beta$-glucosidase production reached maximum $(183 \mathrm{U} / \mathrm{g})$ on 7 th day of incubation. Various fungi have been reported to produce maximum cellulase at different times; therefore direct comparison of time-dependent changes is not possible (Singhania et al., 2010). Our results are in accordance with those by Raghuwanshi et al. (2014), who recorded that maximum FPase and CMCase were exhibited on 4th day of incubation, while $\beta$-glucosidase production reached maximum on 7th day of incubation by Trichoderma asperellum
RCK2011 and mutant strain SR1-7 under SSF. Similar results were obtained by Gao et al. (2008) who stated that the maximum FPase and CMCase production was shown by $A$. terreus M1 1 under SSF after 4 days.

\section{Effect of inoculum level}

The effect of the inoculum level on cellulase production under SSF was evaluated at the corn cob to moisture ratio of 1:3. The temperature was kept at $45^{\circ} \mathrm{C}$, the initial $\mathrm{pH}$ for the wild-type and mutant strains was 10 and the incubation period was 4 days for FPase and CMCase production and 7 days for $\beta$-glucosidase production for both strains. The inoculum size $(10 \sim 50 \%$, v/w) showed noticeable effect on cellulase production by A. terreus AUMC 10138 and M-17, under SSF (Table 5). The results showed that cellulase production by the wild-type and mutant strains of $A$. terreus increased with the increase of the initial inoculum 
Table 5 - Effect of the inoculum level on alkaline cellulase production by wild-type A. terreus AUMC 10138 and its mutant strain M-17 under SSF.

\begin{tabular}{|c|c|c|c|c|c|c|}
\hline \multirow[t]{3}{*}{ Inoculum level (v/w) } & \multicolumn{6}{|c|}{ Enzyme yield (U/g dry carbon source) } \\
\hline & \multicolumn{2}{|c|}{ CMCase } & \multicolumn{2}{|c|}{ FPase } & \multicolumn{2}{|c|}{$\beta$-Glucosidase } \\
\hline & Wild & Mutant & Wild & Mutant & Wild & Mutant \\
\hline $10 \%$ & $425 \pm 2$ & $850 \pm 4$ & $177 \pm 3$ & $375 \pm 4$ & $80 \pm 2$ & $166 \pm 5$ \\
\hline $20 \%$ & $510 \pm 4$ & $1,014 \pm 11$ & $217 \pm 4$ & $433 \pm 2$ & $92 \pm 3$ & $183 \pm 4$ \\
\hline $30 \%$ & $612 \pm 3$ & $1,150 \pm 8$ & $278 \pm 2$ & $460 \pm 5$ & $148 \pm 8$ & $242 \pm 9$ \\
\hline $40 \%$ & $905 \pm 6$ & $1,783 \pm 7$ & $395 \pm 6$ & $729 \pm 7$ & $126 \pm 5$ & $217 \pm 5$ \\
\hline $50 \%$ & $831 \pm 2$ & $1,662 \pm 5$ & $334 \pm 5$ & $644 \pm 3$ & $113 \pm 6$ & $203 \pm 8$ \\
\hline
\end{tabular}

level from $10 \sim 50 \%(\mathrm{v} / \mathrm{w})$. The wild-type strain showed the maximum production of FPase $(395 \mathrm{U} / \mathrm{g})$ and CMCase (905 U/g) at the $40 \%$ (v/w) inoculum level, whereas $\beta$-glucosidase production $(148 \mathrm{U} / \mathrm{g})$ peaked at the $30 \%(\mathrm{v} / \mathrm{w})$ inoculum level. Also, mutant strain M-17 produced maximum FPase $(729 \mathrm{U} / \mathrm{g})$ and CMCase $(1,783 \mathrm{U} / \mathrm{g})$ at the $40 \%$ $(\mathrm{v} / \mathrm{w})$ inoculum level and maximum $\beta$-glucosidase (242 $\mathrm{U} / \mathrm{g})$ at the $30 \%(\mathrm{v} / \mathrm{w})$ inoculum level. The results revealed the importance of the inoculum level in SSF. Higher inoculum levels increased the spore numbers per gram of solid substrate, as well as the water content in the medium. Both factors acted to hinder the penetration of oxygen into the solid medium, thus preventing inhibition of fungal growth and cellulase production. At the sametime, a lower inoculum level required more time for the fermentation process to complete in a batch culture (Vu et al., 2011). Studies carried out by several other authors exhibit different levels of inocula for efficient induction of cellulase. This shows that a balance between nutrients and growing cells is necessary for optimum enzyme production (Matkar et al., 2013).

\section{Effect of salinity}

The effect of salinity on cellulase production under was evaluated under the previously optimized SSF conditions. The salinity of the culture medium strongly influenced the extracellular enzyme production by halophiles
(Li and $\mathrm{Yu}, 2013$ ). As shown in Table 6, the effect of different concentrations of $\mathrm{NaCl}$ on the cellulase production by the wild-type and mutant strains of $A$. terreus was evaluated. The wild strain showed optimal FPase, CMCase and $\beta$-glucosidase production $(395,905$ and $148 \mathrm{U} / \mathrm{g}$, respectively) at $5 \% \mathrm{NaCl}$. Our results are in accordance with those by Wang et al. (2009) who recorded the maxium cellulase production by halophilic bacterium Salinivibrio sp. NTU05 isolated from soil samples taken near Szutsau saltern, in southern Taiwan was obtained in a saline medium containing $5 \% \mathrm{NaCl}$. Likewise, the strain $\mathrm{M}-17$ exhibited the maxium FPase, CMCase and $\beta$-glucosidase production (729, 1,783 and $342 \mathrm{U} / \mathrm{g}$ respectively) at $5 \% \mathrm{NaCl}$. These results clearly revealed the halophilic nature of $A$. terreus AUMC 10138 and mutant M-17, for which salt appeared to be a prerequisite for enzyme production. Halophiles can survive in hypersaline habitats because of their ability to maintain osmotic balance. They accumulate salts such as sodium or potassium chloride $(\mathrm{NaCl}$ or $\mathrm{KCl})$ up to concentrations that are isotonic with the environment. Accordingly, exoenzymes from halophiles must tollerate with high salt concentrations (Kamekura, 1998).

\section{Comparison of cellulases production under SSF}

Comparison of cellulase activities produced by $A$. terreus AUMC 10138 and its mutant strain M-17 under

Table 6 - Effect of different concentrations of $\mathrm{NaCl}$ on alkaline cellulase production by wild-type $A$. terreus AUMC 10138 and its mutant strain M-17 under SSF.

\begin{tabular}{|c|c|c|c|c|c|c|}
\hline \multirow[t]{3}{*}{$\mathrm{NaCl}(\%)$} & \multicolumn{6}{|c|}{ Enzyme yield (U/g dry carbon source) } \\
\hline & \multicolumn{2}{|c|}{ CMCase } & \multicolumn{2}{|c|}{ FPase } & \multicolumn{2}{|c|}{$\beta$-Glucosidase } \\
\hline & Wild & Mutant & Wild & Mutant & Wild & Mutant \\
\hline $0 \%$ & $633 \pm 3$ & $945 \pm 4$ & $209 \pm 3$ & $413 \pm 4$ & $102 \pm 2$ & $172 \pm 4$ \\
\hline $2.5 \%$ & $756 \pm 7$ & $1,274 \pm 11$ & $355 \pm$ & $556 \pm 2$ & $127 \pm 3$ & $209 \pm 3$ \\
\hline $5 \%$ & $905 \pm 6$ & $1,783 \pm 7$ & $395 \pm 6$ & $729 \pm 7$ & $148 \pm 8$ & $342 \pm 1$ \\
\hline $7.5 \%$ & $777 \pm 4$ & $1,511 \pm 7$ & $347 \pm 6$ & $666 \pm 7$ & $131 \pm 6$ & $283 \pm 5$ \\
\hline $10.0 \%$ & $624 \pm 6$ & $1,236 \pm 5$ & $259 \pm 5$ & $511 \pm 3$ & $114 \pm 7$ & $175 \pm 3$ \\
\hline $12.5 \%$ & $447 \pm 3$ & $1,096 \pm 9$ & $187 \pm 2$ & $378 \pm 5$ & $89 \pm 2$ & $153 \pm 2$ \\
\hline
\end{tabular}


Table 7 - Comparison of cellulases production by wild-type A. terreus AUMC 10138 and its mutant strain M-17 with other fungi under SSF.

\begin{tabular}{|c|c|c|c|c|c|}
\hline \multirow[t]{2}{*}{ Microorganism } & \multirow[t]{2}{*}{ Carbon source } & \multicolumn{3}{|c|}{ Enzyme yield (U/g dry carbon source) } & \multirow[t]{2}{*}{ Reference } \\
\hline & & CMCase & FPase & $\beta$-Glucosidase & \\
\hline A. niger $\mathrm{KK} 2$ & Rice straw & 129 & 19.5 & 100 & (Kang et al., 2004) \\
\hline A. niger $\mathrm{MTCC}$ & Wheat bran & 135.4 & 4.6 & 21.4 & (Sukumaran et al., 2009) \\
\hline Penicillium citrinum YS40-5 & Rice bran & 180.3 & 3.8 & 159.1 & (Ng et al., 2010) \\
\hline Trichoderma reesi $\mathrm{RUT}$ & Wheat bran & 299.6 & 22.8 & 4.5 & (Sukumaran et al., 2009) \\
\hline Fusarium oxysporum & Corn stover & 304 & - & 0.140 & (Panagiotou et al., 2003) \\
\hline A. fumigatus Z5 & Corn stover & 526.3 & 144.6 & - & (Liu et al., 2011) \\
\hline A. terreus M11 & Corn stover & 563 & 231 & 119 & (Gao et al., 2008) \\
\hline Thermoascus aurantiacus & Wheat straw & 1,572 & & 101.6 & (Kalogeris et al., 2003a) \\
\hline Thermoascus aurantiacus & Wheat straw & 1,709 & 5.5 & 79 & (Kalogeris et al., 2003b) \\
\hline A. terreus AUMC 10138 & Corn stover & 905 & 395 & 148 & This study \\
\hline A. terreus $\mathrm{M}-17$ & Corn stover & 1,783 & 729 & 342 & This study \\
\hline
\end{tabular}

SSF with those reported for other cellulase producing fungi showed that the yields of the cellulases produced by this work were much higher than those produced by other fungi (Table 7). In fact, the comparisons of cellulase activities produced by different laboratories is not readily made in quantitative manner as no standard conditions of cellulase activity assay have yet been adopted. Therefore only relative comparison is provided in this paper.

\section{References}

Adsul MG, Bastawde KB, Varma AJ et al. (2007) Strain improvement of Penicillium janthinellum NCIM 1171for increased cellulase production. Bioresour Technol 98:1467-1473.

Emtiazi G, Naghavi N, Bordbar A (2001) Biodegradation of lignocellulosic waste by Aspergillus terreus. Biodegradation 12:259-263.

Gao J, Weng H, Zhu D et al. (2008) Production and characterization of cellulolytic enzymes from the thermoacidophilic fungal Aspergillus terreus M11 under solid-state cultivation of corn stover. Bioresour Technol 99:7623-7629.

Grajek W (1987) Comparative studies on the production of cellulases by thermophilic fungi in submerged and solid-state fermentation. Appl Microbiol Biotechnol 26:126-129.

Grant WD, Jones BE (2000) Alkaline environments. In: Lederberg $\mathrm{J}$ (ed) Encyclopaedia of Microbiology. $2^{\text {nd }}$ ed. Academic Press, New York p.126-133.

Hong J, Tamaki H, Akiba S et al. (2001) Cloning of a gene encoding a highly stable endo-b-1,4-glucanase from Aspergillus niger and its expression in yeast. J Biosci Bioeng 92:434441.

Juhasz T, Szengyel Z, Szijarto N et al. (2004) Effect of pH on cellulase production of Trichoderma reesei RUT C30. Appl Biochem Biotechnol 113-116:201-211.

Juhasz T, Szengyel Z, Reczey K et al. (2005) Characterization of cellulases and hemicellulases produced by Trichoderma reesei on various carbon sources. Process Biochem 40:3519-3525.

Kalogeris E, Christakopoulos P, Katapodis P et al. (2003a) Production and characterization of cellulolytic enzymes from the thermophilic fungus Thermoascus aurantiacus under solid state cultivation of agricultural wastes. Process Biochem 38:1099-1104.

Kalogeris E, Iniotaki F, Topakas E et al. (2003b) Performance of an intermittent agitation rotating drum type bioreactor for solid-state fermentation of wheat straw. Bioresour Technol 86:207-213.

Kamekura M (1998) Diversity of extremely halophilic bacteria. Extremophiles 2:289-295.

Kang SW, Park YS, Lee JS et al. (2004) Production of cellulases and hemicellulases by Aspergillus niger KK2 from lignocellulosic biomass. Bioresour Technol 91:153-156.

Kasana RC, Salwan R, Dhar H et al. (2008) A rapid and easy method for the detection of microbial cellulases on agar plates using gram's iodine. Curr Microbiol 57:503-507.

Li X, Yu HY (2013) Halostable cellulase with organic solvent tolerance from Haloarcula sp. LLSG7 and its application in bioethanol fermentation using agricultural wastes. J Ind Microbiol Biotechnol 40:1357-1365.

Li YH, Ding M, Wang J et al. (2006) A novel thermoacidophilic endoglucanase, Ba-EGA, from a new cellulosedegrading bacterium, Bacillus sp. AC-1. Appl Microbiol Biotechnol 70:430-436.

Liu D, Zhang R, Yang X et al. (2011) Thermostable cellulase production of Aspergillus fumigatus Z5 under solid-state fermentation and its application in degradation of agricultural wastes. Int Biodeter Biodegr 65:717-725.

Louime C, Uckelmann H (2008) Cellulosic ethanol: securing the planet future energy needs. Int J Mol Sci 9:838-841.

Maheshwari R, Bharadwaj G, Bhat M (2000) Thermophilic fungi: their physiology and enzymes. Microbiol Mol Biol Rev 64:461-488.

Matkar K, Chapla D, Divecha J et al. (2013) Production of cellulase by a newly isolated strain of Aspergillus sydowii and its optimization under submerged fermentation. Int Biodeterior Biodegrad 78:24-33

Miller GL (1959) Use of dinitrosalicylic acid reagent for determination of reducing sugar. Anal Biochem 31:426-428.

Mirzaakhmedov S, Ziyavitdinov Z, Akhmedova Z et al. (2007) Isolation, purification, and enzymatic activity of cellulase 
components of the fungus Aspergillus terreus. Chem Nat Compd 43:594-597.

Ng IS, Li CW, Chan SP et al. (2010) High-level production of a thermoacidophilic beta-glucosidase from Penicillium citrinum YS40-5 by solid-state fermentation with rice bran. Bioresour Technol 101:1310-1317.

Ong LG, Abd-Aziz S, Noraini S et al. (2004) Enzyme production and profile by Aspergillus niger during solid substrate fermentation using palm kernel cake as substrate. Appl Biochem Biotechnol 118:73-79.

Panagiotou G, Kekos D, Macris BJ et al. (2003) Production of cellulolytic and xylanolytic enzymes by Fusarium oxysporum grown on corn stover in solid state fermentation. Ind Crop Prod 18:37-45.

Parekh S, Vinci VA, Strobel RJ (2004) Improvement of microbial strains and fermentation processes. Appl Microbiol Biotechnol 54:287-301.

Raghuwanshi S, Deswal D, Karp M et al. (2014) Bioprocessing of enhanced cellulase production from a mutant of Trichoderma asperellum RCK2011 and its application in hydrolysis of cellulose. Fuel 124:183-189.

Senthilkumar SR, Ashokkumar B, Raj KC et al. (2005) Optimization of medium composition for alkali-stable xylanase production by Aspergillus fischeri Fxn 1 in solid-state fermentation using central composite rotary design. Bioresour Technol 96:1380-1386.

Singh A, Singh N, Bishnoi NR (2009) Production of cellulases by Aspergillus heteromorphus from wheat straw under submerged fermentation. Int J CivEnviron Eng 1:23-26.

Singhania RR, Sukumaran RK, Patel AK et al. (2010) Advancement and comparative profiles in the production technolo- gies using solid-state and submerged fermentation for microbial cellulases. Enzyme Microb Technol 46:541-549.

Sukumaran RK, Singhania RR, Mathew GM et al. (2009) Cellulase production using biomass feed stock and its application in lignocellulose saccharification for bio-ethanol production. Renewable Energy 34:421-424.

Vu VH, Pham TA, Kim K (2011) Improvement of Fungal Cellulase Production by Mutation and Optimization of Solid State Fermentation. Mycobiology 39:20-25.

Wang CY, Hsieh YR, Ng CC et al. (2009) Purification and characterization of a novel halostable cellulase from Salinivibrio sp. strain NTU-05. Enzyme Microb Technol 44:373-379.

Wang XJ, Bai JG, Liang YX (2006) Optimization of multienzyme production by two mixed strains in solid-state fermentation. Appl Microbiol Biotechnol 73:533-540.

Xin F, Geng A (2010) Horticultural west as the substrate for cellulase and hemicellulase production by Trichoderma reesei under solid-state fermentation. Appl Biochem Biotechnol 162:295-306.

Yang S (2001) Chemistry of Plant Fibers. third ed. China Light Industry Press. Beijing.

Yang SQ, Yan QJ, Jiang ZQ et al. (2006) High-level of xylanase production by the thermophilic Paecilomyces themophila $\mathrm{J} 18$ on wheat straw in solid-state fermentation. Bioresour Technol 97:1794-1800.

Zhang YHP, Himmel ME, Mielenz JR (2006) Outlook for cellulase improvement: screening and selection strategies. Biotechnol Adv 24:452-481.

\section{Associate Editor: Miguel Juan Beltran-Garcia}

All the content of the journal, except where otherwise noted, is licensed under a Creative Commons License CC BY-NC. 